\title{
YEAST IN BIOPHARMACEUTICAL SCIENCES: VISUALISATION OF RESEARCH LANDSCAPE AND A BIBLIOMETRIC ANALYSIS
}

\author{
JIE YEE WAN 1 , CHIA WEI PHAN $1,2,3^{*}$, NOORHIDAWATI ABDULLAH ${ }^{4}$, \\ YASAASWINI APPARAO ${ }^{1}$ AND IAN MACREADIE ${ }^{5}$ \\ ${ }^{1}$ Department of Pharmaceutical Life Sciences, Faculty of Pharmacy, \\ Universiti Malaya, Kuala Lumpur, Malaysia \\ ${ }^{2}$ Clinical Investigation Centre, University Malaya Medical Centre, \\ Kuala Lumpur, Malaysia \\ ${ }^{3}$ Mushroom Research Centre, Universiti Malaya, Kuala Lumpur, Malaysia \\ ${ }^{4}$ Department of Library Science \& Information, Faculty of Computer Science \\ \& Information Technology, Universiti Malaya, Kuala Lumpur, Malaysia \\ ${ }^{5}$ School of Science, RMIT University, Bundoora, Victoria, Australia
}

Published online: 24 May 2021

To cite this article: JIE YEE WAN, CHIA WEI PHAN, NOORHIDAWATI ABDULLAH, YASAASWINI APPARAO \& IAN MACREADIE (2021) Yeast in biopharmaceutical sciences: Visualisation of research landscape and a bibliometric analysis, Malaysian Journal of Pharmaceutical Sciences, 19(1): 133-144, https://doi.org/10.21315/mjps2021.19.1.10

To link to this article: https://doi.org/10.21315/mjps2021.19.1.10

\begin{abstract}
The current study aims to analyse the trend in yeast research within the domain of biopharmaceutical sciences. Bibliographic information of the 1,000 most cited publications on yeast research in biopharmaceutical science was retrieved from the Scopus database. The data was then analysed by using bibliometric approaches. The data indicated a steady increase in publication numbers. The United States, Japan and China were among the highest research output countries. A total of 25 top core journals were identified. The keywords with the highest frequency included production, study and activity. To conclude, the current bibliometric analysis provides information that may be useful in locating research hot spots and gaps in the research area of yeast in biopharmaceutical science.
\end{abstract}

Keywords: Yeast, Bibliometric, Scientometric, Saccharomyces cerevisiae, VOSviewer

\section{INTRODUCTION}

Biopharmaceuticals are therapeutic substances from biological origins. Also called biologics, they are manufactured in living organisms such as bacteria, yeast and mammalian cells (Rader 2008). Biopharmaceutics, on the other hand, is defined as the study of the chemical and physical properties of drugs and it mainly involves drug absorption process (Panchagnula and Thomas 2000).

"Corresponding author: phancw@um.edu.my

(C) Penerbit Universiti Sains Malaysia, 2021. This work is licensed under the terms of the Creative Commons Attribution (CC BY) (http://creativecommons.org/licenses/by/4.0/). 
Yeast is a unicellular organism that shares the characteristics of eukaryotes where the fundamental cellular mechanisms of replication, cell division, recombination and metabolism are highly conserved between yeast and higher eukaryotes, including mammals (Kim, Yoo and Kang 2015; Laukens, De Visscher and Callewaert 2015). One of the most highlighted advantages of yeast is that the culture of yeast can be done easily and it has a fast growth rate with a propagation time comparable to that of bacterial cells (Feldmann 2012; Huang, Bao and Nielsen 2014). Thus, the high productivity of yeast cells is effective in large-scale production of biopharmaceutical products (Botstein and Fink 2011).

Yeast is beneficial as a cell factory for the pharmaceutical production of insulin, human serum albumin and vaccines (Nielsen 2013). Saccharomyces cerevisiae is considered the best understood organism as it is the first eukaryotic organism to have its whole genome completely sequenced (Goffeau et al. 1996). Therefore, genetic modifications can be done easily as the immense amount of information is readily available (Huang, Bao and Nielsen 2014). Furthermore, yeast contains cellular organelles, that allow the production and folding of human proteins to be done correctly, including post-translational modifications. In addition, yeast is recognised as an ideal host for foreign protein secretion because it can produce high levels of protein and lower costs for downstream purification (Macreadie 2007). With the advancement of synthetic biology, S. cerevisiae has been genetically reprogrammed to produce and secrete the antibiotic penicillin (Awan et al. 2017). In the past decades, alternative hosts for biopharmaceutical production have been established from unconventional yeast species such as Hansenula polymorpha, Pichia pastoris, Yarrowia lipolytica, Kluyveromyces marxianus, Kluyveromyces lactis and Scheffersomyces stipitis (Kim, Yoo and Kang 2015; Lobs, Schwartz and Wheeldon 2017).

Bibliometric analysis is defined as 'the application of mathematics and statistical methods to books and other media of communication' (Pritchard 1969). In the past five decades, scientific publication has grown rapidly and become increasingly specialised. This has enhanced the difficulty in the evaluation of scientific research (Belter 2015; Alberts et al. 2014). Fortunately, bibliometric methods can be used to facilitate the assessment and appraisal of scholarly publications (Belter 2015). VOSviewer is an example of a bibliometric tool that employs the new mapping technique called visualisation of similarities (VOS) (Van Eck et al. 2010). VOS enables data mining and is capable of producing a large complex map from a large amount of data. In addition, VOSviewer was designed to make constructing and visualising bibliometric networks easy and it is available freely.

To the best of our knowledge, there is no bibliometric study so far to present the knowledge structure and development of yeast research in biopharmaceutical sciences, in a global setting. Therefore, in this study, we aimed to analyse and present an overview of the research trend in yeast research of biopharmaceutical science by a bibliometric method. The specific research questions that were addressed in the study are as follows: (1) What are the publications trends on yeast research in biopharmaceutical science from 1961 to 2019 in terms of influential countries, international collaboration, and productive journals? and (2) What are the specific research areas in yeast research of biopharmaceutical science that emerge from the data? 


\section{METHODS}

\section{Data Collection}

Scopus is a multidisciplinary subscription database created and hosted by Elsevier. The Scopus database was selected to extract bibliometric data as previously reported by Chan et al. (2020). The data collected included publication details and citations of the 1,000 most-cited papers on yeast research for biopharmaceutical science. The data was extracted by searching the Scopus database with the following string: TITLE-ABS-KEY (Yeast) AND (Biopharmaceutical) OR (Pharmaceutical). The string searched for all the publications that contain any of these terms in their title, abstract or keywords.

\section{Bibliometrical Analysis}

The obtained data were analysed with regards to the publication year, publishing country, international collaboration and terms frequency (Chan et al. 2020). Bradford's law of scattering was applied only on the most-cited papers (excluding books and chapters) to identify the core journals as previously described by Yeung, Goto and Leung (2018). Keyword co-occurrence analysis was performed based on the terms extracted from the title and abstract of the 1,000 most-cited publications by adopting binary counting (Lozano, Calzada-Infante and Adenso-Díaz 2019). Additionally, VOSviewer was used to visualise the co-authorship analysis based on the countries with the aid of visualisation map (Van Eck and Waltman 2007).

\section{RESULTS AND DISCUSSION}

A total of 2,489 publications were found in the Scopus database from 1939 to May 2019. Among the 2,489 publications, the 1,000 most-cited ones were published during 1961 to 2019 (Figure 1A). A sharp growth trend was observed in 2001 to 2015, especially from 2011 to 2015 .

We selected Scopus because Scopus has more journal coverage compared to Web of Science (WoS) and PubMed (Gorraiz and Schloegl 2008; Boshoff and Akanmu 2017). It is also noteworthy that Scopus included 1.04 times more articles than WoS (Vieira and Gomes 2009). Bartol and Mackiewicz-Talarczyk (2015) also reported that about two-thirds of the documents referenced in WoS and Scopus may be found in both databases. Therefore, it would create 'redundancy' when combining both online databases for a bibliometrical analysis. Google Scholar, on the other hand, when interrogated in this study, resulted in the highest number of documents. Google Scholar, given its free-of-charge nature, was shown to be practicing the 'quantity/breadth principle' and this could potentially serve as a weakness for bibliometrical purposes. Aguillo (2012) argued that the larger coverage of Google Scholar has been overrepresented by popular scientific literature, unpublished reports, and even teaching materials that make it 'lacks the quality control needed for its use as a bibliometric tool'. Finally, PubMed, is reported to have 'a smaller number of documents due to its narrower scope and coverage' (Alryalat, Malkawi and Momani 2019). 


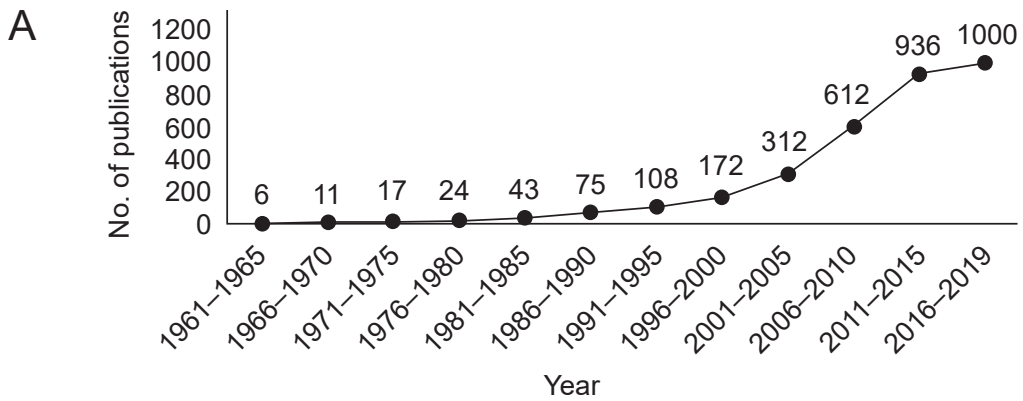

B

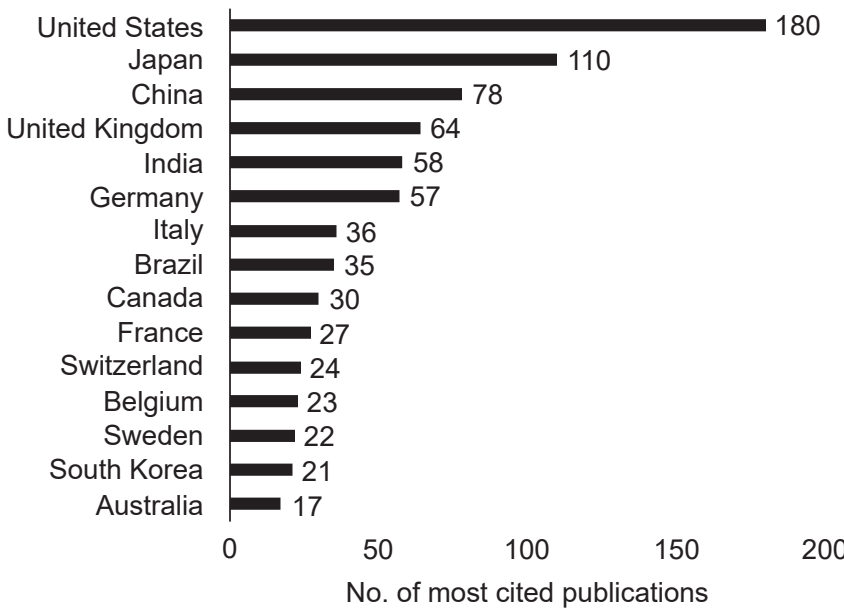

C

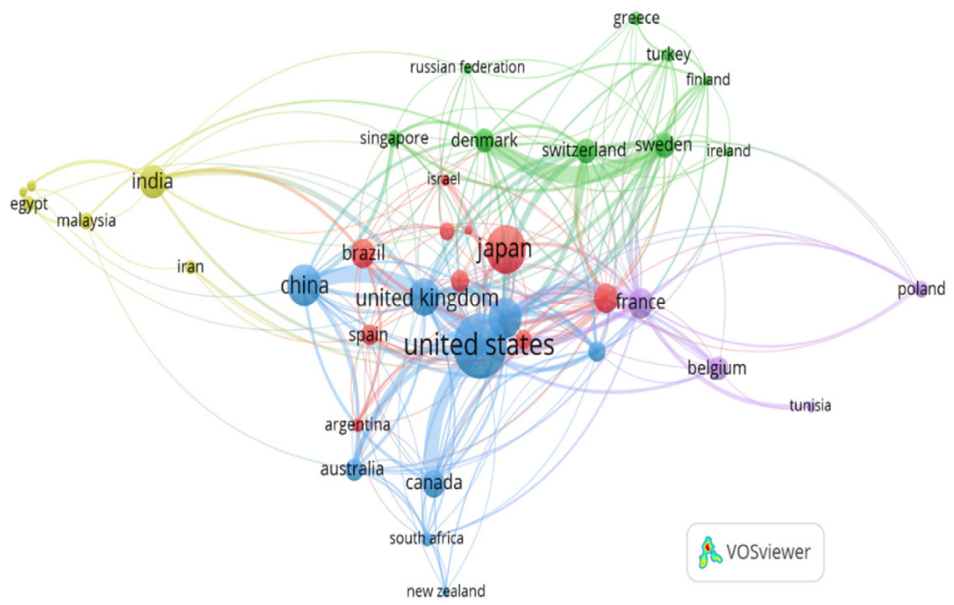

Figure 1: The trend of publications on yeast research in biopharmaceutical science. (A) The accumulated publications of the 1,000 top-cited publications across the year 1961 to year 2019; (B) The top 15 countries publishing the 1,000 most-cited papers; (C) The co-authorship analysis according to countries. 
Next, to assess the role of geographical distribution, VOS analysis was performed based on countries and/or regions. The 15 most productive countries included eight European countries, four Asian countries, the United States, Brazil and Australia (Figure 1B). The leading country is the United States, which comprised $18 \%(n=180)$ of the total publications, followed by Japan $(n=110,11 \%)$, China $(n=78,7.8 \%)$, United Kingdom ( $n=64,6.4 \%)$, and India $(n=58,5.8 \%)$. With the goal to reflect the degree of collaboration between countries as well as the influential countries in this field, country co-authorship analysis was performed using VOSviewer. As shown in Figure $1 \mathrm{C}$, the bigger nodes represent the influential countries with a higher number of publications. The links between the nodes represent the cooperative relationship among the countries. The distances between the nodes and the thickness of links indicate the level of cooperation among countries. It can be observed that most of the international collaborations were between the developed countries.

Based on Bradford's law of scattering analysis, the top cited papers were published in a total of 464 journals. However, only the top 25 core and active journals are shown in Table 1. The most prolific journal in this field was found to be the Chemical and Pharmaceutical Bulletin which published the highest number of papers ( $n=51,5.2 \%)$ on yeast research in biopharmaceutical sciences, followed by the Applied Microbiology and Biotechnology, and the Biological and Pharmaceutical Bulletin. As shown in Table 1, the impact factors (IF) of these 25 core journals range from 1.258 to 9.504 . The Proceedings of the National Academy of Sciences of United States of America has the highest impact factor (IF = 9.504), followed by the Current Opinion in Biotechnology (IF = 8.380) and the Metabolic Engineering (IF = 7.674). Notably, the Proceedings of the National Academy of Sciences of United States of America also has the highest SCImago Journal Rank (SJR), Source Normalized Impact per Paper (SNIP) and CiteScore values (Table 1).

In this study, the Chemical and Pharmaceutical Bulletin, despite having a lower impact factor than the Applied Microbiology and Biotechnology, was shown to publish the highest number of papers on the investigated domain. This could be due to its more specific aims and scopes, ranging from chemical biology to pharmaceutical engineering. Meanwhile, the Applied Microbiology and Biotechnology has a wider scope which focuses not only on prokaryotic or eukaryotic cells, but also on genomics and proteomics; and more. Chan et al. (2020) studied the relationship between the impact factor and publication count regarding the research on culinary and medicinal mushrooms. The results clearly indicated that there was an insignificant negative correlation between the two variables. It is thus postulated that the decision of a choice of journal could be largely due to other factors besides the journal's performance. 


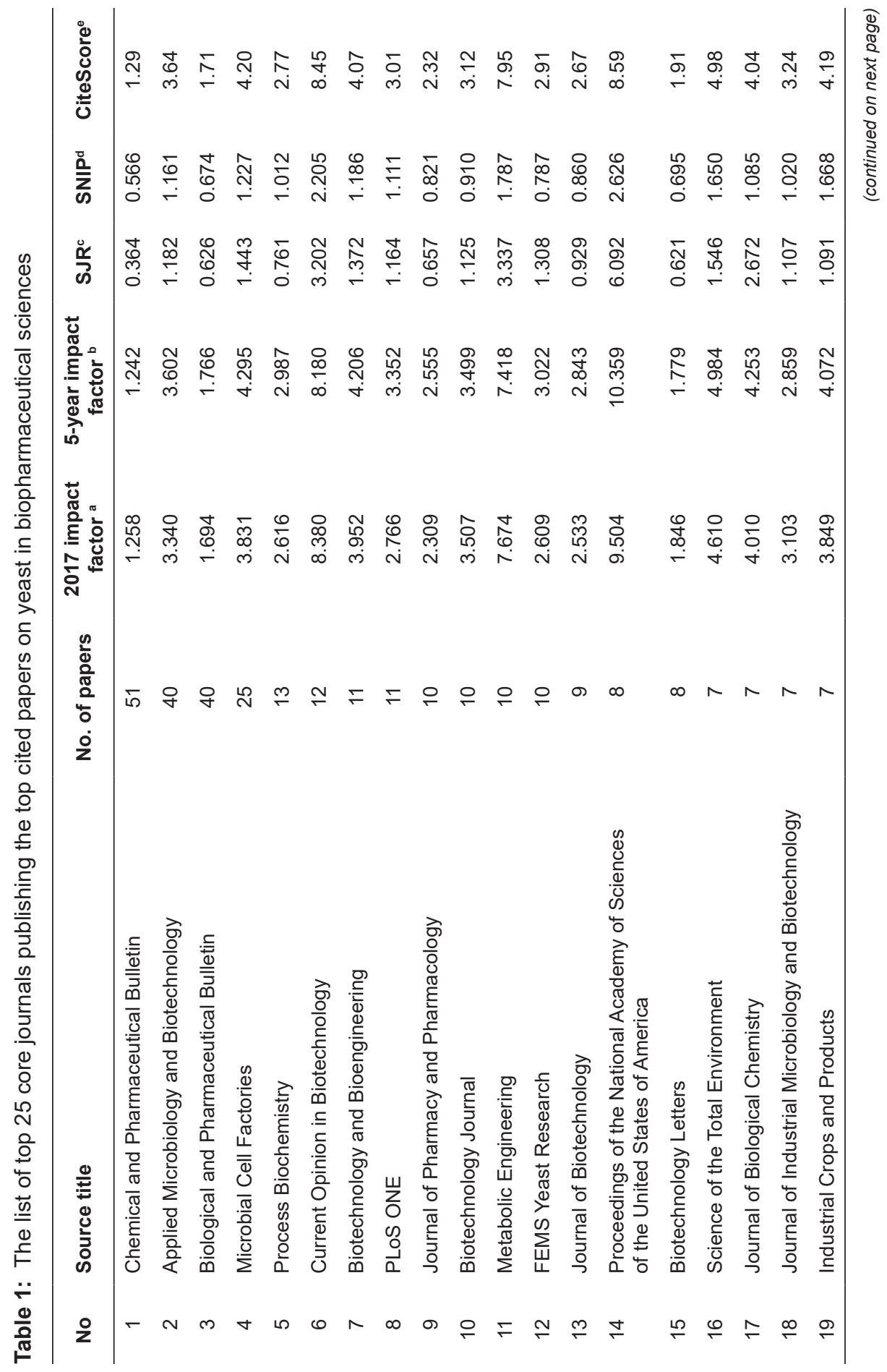

Malay J Pharm Sci, Vol. 19, No. 1 (2021): 133-144 


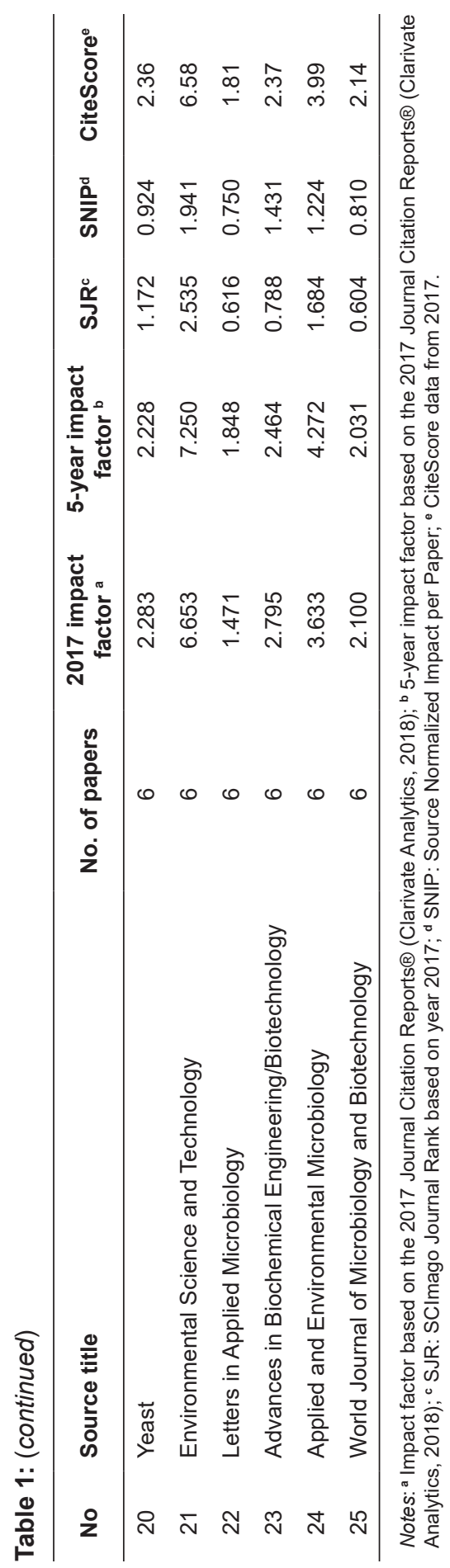

Malay J Pharm Sci, Vol. 19, No. 1 (2021): 133-144 
A network map of the most frequently appeared terms was generated by the VOSviewer software to visualise the recurring terms (Figure 2). VOSviewer analysis shows that the percentage of yeast related publications in the field of biopharmaceutical has been soaring in recent years. A total of 47 terms met the threshold with a minimum number of occurrences at 50 . As stipulated in Figure 2, the distance between the nodes refers to the strength of relation between two nodes. A closer distance between two nodes reveals a stronger relation between them. The thicker the line is, the greater the co-occurrence of terms.

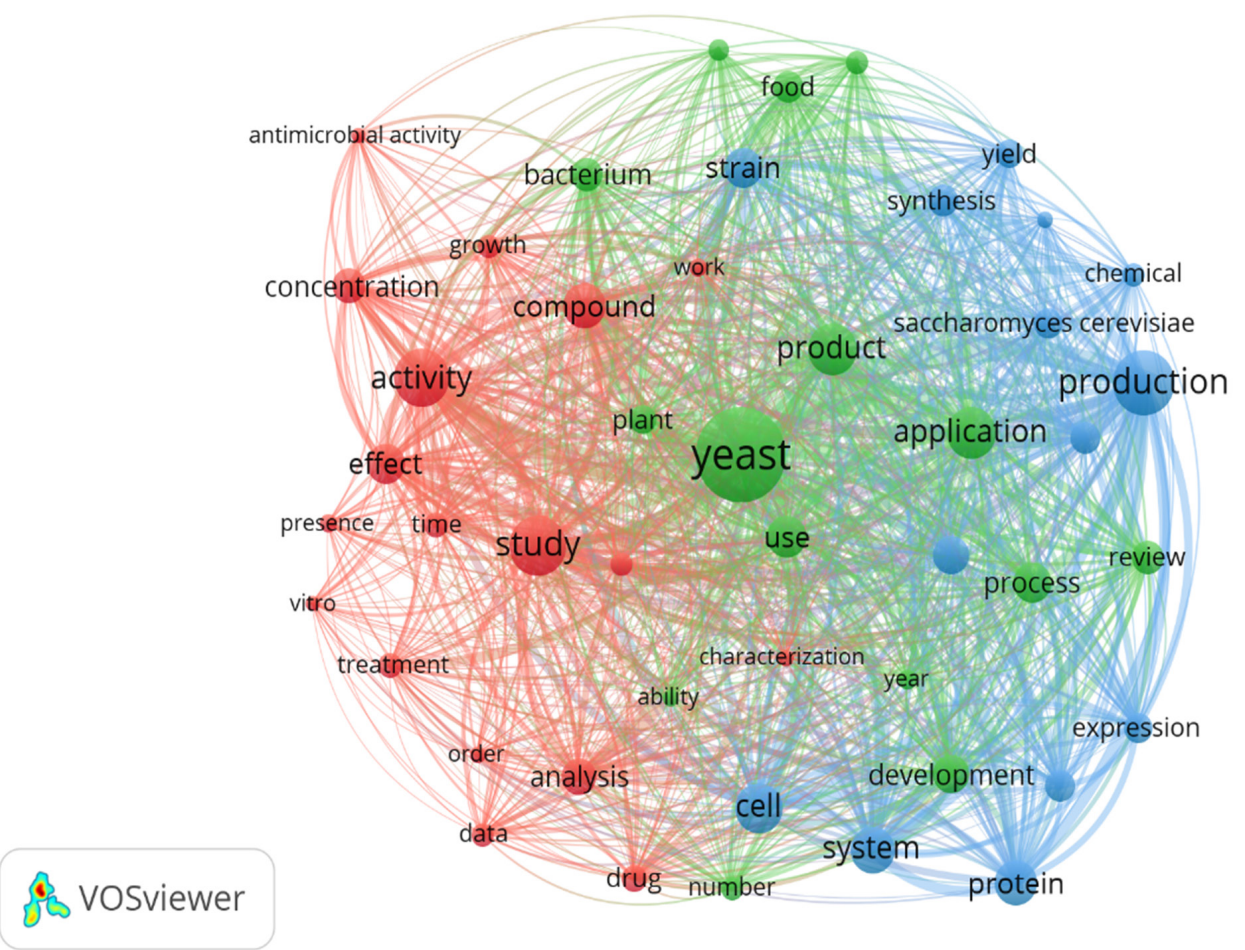

Figure 2: The co-occurrence network of the most frequently appearing terms in the title and abstract of the 1,000 top-cited publications.

It is noted that yeast, cell, strain, activity and effect are among the most repeated terms in 2006. Post 2006, the trend was more focused on application, production, pharmaceutical and processes (Table 2). The keyword co-occurrence analysis can effectively reflect the research hotspots in different fields, providing auxiliary support for scientific research (Cheng et al. 2018). From these terms, we found that the current attention on yeast research in pharmaceutical science mainly focuses on biochemistry, genetic and molecular biology, as well as in the subject area of pharmacology, toxicology, and pharmaceutics. Indeed, yeast has been used as a system to study the antimicrobial, anti-inflammatory and estrogenic activity of some pharmaceutical ingredients and excipients as outlined by Korhola (2018). 
Table 2: The top 20 terms that appeared the most in the title and abstract of the 1,000 topcited publications.

\begin{tabular}{lccc}
\hline Terms & Occurrences & Total link strength & Average published year \\
\hline Yeast & 594 & 4,442 & 2006 \\
Production & 370 & 3,161 & 2009 \\
Study & 337 & 2,693 & 2007 \\
Activity & 321 & 2,382 & 2007 \\
Application & 280 & 2,369 & 2008 \\
Product & 276 & 2,298 & 2007 \\
Cell & 263 & 2,117 & 2006 \\
System & 249 & 2,011 & 2007 \\
Compound & 235 & 1,881 & 2007 \\
Protein & 231 & 1,790 & 2008 \\
Use & 215 & 1,736 & 2005 \\
Effect & 206 & 1,631 & 2006 \\
Strain & 206 & 1,723 & 2007 \\
Process & 197 & 1,723 & 2008 \\
Development & 194 & 1,649 & 2008 \\
Pharmaceutical & 186 & 1,598 & 2009 \\
Analysis & 177 & 1,413 & 2008 \\
Concentration & 167 & 1,295 & 2006 \\
Bacterium & 163 & 1,451 & 2006 \\
Review & 158 & 1,318 & 2009 \\
\hline
\end{tabular}

\section{CONCLUSION}

To conclude, this study can serve as an evidence-based reference for industries and researchers working with yeasts to identify the emerging research areas and hence facilitate the decision-making in drafting future research work. This study also provides insights to locate current research hotspots and gaps in yeast research. With this approach, scholars can appreciate the most cited content of the yeast research in biopharmaceutical science, as well provide evidence of the impact of research outputs when applying for research funding, finding new and emerging areas of research, and identifying potential research collaborators.

\section{ACKNOWLEDGEMENTS}

The authors would like to thank the Universiti Malaya Main Library and TJ Danaraj Medical Library for the online database services. 


\section{REFERENCES}

AGUILLO, I. F. (2012) Is Google Scholar useful for bibliometrics? A webometric analysis, Scientometrics, 91: 343-351. https://doi.org/10.1007/s11192-011-0582-8

ALBERTS, B., KIRSCHNE, M. W., TILGHMAN, S. \& VARMUS, H. (2014) Rescuing US biomedical research from its systemic flaws, Proceedings of the National Academy of Science of the United States of America, 111: 5773-5777. https://doi.org/10.1073/ pnas. 1404402111

ALRYALAT, S. A. S., MALKAWI, L. W. \& MOMANI, S. M. (2019) Comparing bibliometric analysis using PubMed, Scopus, and Web of Science databases, Journal of Visualized Experiments, 152: e58494. https://doi.org/10.3791/58494

AWAN, A., BLOUNT, B., BELL, D., SHAW, W. M., HO, C. H., MCKIERNAN, R. M. et al. (2017) Biosynthesis of the antibiotic nonribosomal peptide penicillin in baker's yeast, Nature Communications, 8: 15202. https://doi.org/10.1038/ncomms15202

BARTOL, T. \& MACKIEWICZ-TALARCZYK, M. (2015) Bibliometric analysis of publishing trends in fiber crops in Google Scholar, Scopus, and Web of Science, Journal of Natural Fibers, 12(6): 531-541. https://doi.org/10.1080/15440478.2014.972000

BELTER, C. W. (2015) Bibliometric indicators: Opportunities and limits, Journal of Medical Library Association, 103: 219-221. https://doi.org/10.3163/1536-5050.103.4.014

BOSHOFF, N. \& AKANMU, M. (2017) Scopus or Web of Science for a bibliometric profile of pharmacy research at a Nigerian university? South African Journal of Libraries and Information Science, 83(2). https://doi.org/10.7553/83-2-1682

BOTSTEIN, D. \& FINK, G. R. (2011) Yeast: An experimental organism for 21st century biology, Genetics, 189: 695-704. https://doi.org/10.1534/genetics.111.130765

CHAN, X. H., SABARATNAM, V., ABDULLAH, N. \& PHAN, C. W. (2020) A 53-year bibliometric and scientometric analysis of research in culinary and medicinal mushrooms, International Journal of Medicinal Mushrooms, 22(6): 521-534. https://doi.org/10.1615/ IntJMedMushrooms.2020035031

CHENG, F. F., HUANG, Y. W., YU, H. C. \& WU, C. S. (2018) Mapping knowledge structure by keyword co-occurrence and social network analysis: Evidence from Library Hi Tech between 2006 and 2017, Library Hi Tech, 36: 636-650. https://doi.org/10.1108/LHT-012018-0004

FELDMANN, H. (2012) Yeast cell architecture and functions. IN: Yeast: Molecular and Cell Biology, $2^{\text {nd }}$ ed, pp. 5-24 (Weinheim, Germany: Wiley-VCH). https://doi. org/10.1002/9783527659180.ch2

GOFFEAU, A., BARRELL, B. G., BUSSEY, H., DAVIS, R. W., DUJON, B., FELDMANN, H. et al. (1996) Life with 6000 genes, Science, 274(5287): 563-567. https://doi.org/10.1126/ science.274.5287.546

Malay J Pharm Sci, Vol. 19, No. 1 (2021): 133-144 
GORRAIZ, J. \& SCHLOEGL, C. (2008) A bibliometric analysis of pharmacology and pharmacy journals: Scopus versus Web of Science, Journal of Information Science, 34(5): 715-725. https://doi.org/10.1177/0165551507086991

HUANG, M., BAO, J. \& NIELSEN, J. (2014) Biopharmaceutical protein production by Saccharomyces cerevisiae: Current state and future prospects, Pharmaceutical Bioprocessing, 2: 167-182. https://doi.org/10.4155/pbp.14.8

KIM, H., YOO, S. J. \& KANG, H. A. (2015) Yeast synthetic biology for the production of recombinant therapeutic proteins, FEMS Yeast Research, 15: 1-16. https://doi. org/10.1111/1567-1364.12195

KORHOLA, M. (2018) Between science and industry-applied yeast research, FEMS Yeast Research, 18(2): 8. https://doi.org/10.1093/femsyr/foy008

LAUKENS, B., DE VISSCHER, C. \& CALLEWAERT, N. (2015) Engineering yeast for producing human glycoproteins: Where are we now? Future Microbiology, 10(1): 21-34. https://doi.org/10.2217/fmb.14.104

LOBS, A. K., SCHWARTZ, C. \& WHEELDON, I. (2017) Genome and metabolic engineering in non-conventional yeasts: Current advances and applications, Synthetic and Systems Biotechnology, 2: 198-207. https://doi.org/10.1016/j.synbio.2017.08.002

LOZANO, S., CALZADA-INFANTE, L. \& ADENSO-DÍAZ, B. (2019) Complex network analysis of keywords co-occurrence in the recent efficiency analysis literature, Scientometrics, 120: 609-629. https://doi.org/10.1007/s11192-019-03132-w

MACREADIE, I. (2007) Therapeutic products from yeast, Microbiology Australia, 28: 82-84. https://doi.org/10.1071/MA07082

NIELSEN, J. (2013) Production of biopharmaceutical proteins by yeast: Advances through metabolic engineering, Bioengineered, 4: 207-211. https://doi.org/10.4161/bioe.22856

PANCHAGNULA, R. \& THOMAS, N. S. (2000) Biopharmaceutics and pharmacokinetics in drug research, International Journal of Pharmaceutics, 25: 131-150. https://doi.org/10.1016/ S0378-5173(00)00344-6

PRITCHARD, A. (1969) Statistical bibliography or bibliometrics? Journal of Documentation, 25: 348.

RADER, R. (2008) (Re)defining biopharmaceutical, Nature Biotechnology, 26: 743-751. https://doi.org/10.1038/nbt0708-743

VAN ECK, N. J., WALTMAN, L., DEKKER, R. \& VAN DEN BERG, J. (2010) A comparison of two techniques for bibliometric mapping: Multidimensional scaling and VOS, Journal of the American Society for Information Science \& Technology, 6: 2405-2416. https://doi.org/ 10.1002/asi.21421 
VAN ECK, N. J. \& WALTMAN, L. (2007) VOSviewer manual version 1.6.6. 2007. http://www.vosviewer.com/documentation/Manual_VOSviewer_1.6.6.pdf (12 October 2020).

VIEIRA, E. S. \& GOMES, J. A. N. F. (2009) A comparison of Scopus and Web of Science for a typical university, Scientometrics, 81(2): 587-600. https://doi.org/10.1007/s11192-009 $-2178-0$

YEUNG, A. W. K, GOTO, T. K. \& LEUNG, W. K. (2018) Affective value, intensity, and quality of liquid tastants/food discernment in the human brain: An activation likelihood estimation meta-analysis, Neuroimage, 169: 189-199. https://doi.org/10.1016/j.neuroimage .2017.12.034 